\title{
Gorbán D. y Tizziani A. (2019). ¿Cada una en su lugar? Trabajo, género y clase en el servicio doméstico. Buenos Aires: Editorial Biblos
}

Ana Inés Mallimacci Barral

CONICET-Instituto Interdisciplinario de Estudios de Género -

Universidad Nacional Arturo Jauretche, Argentina

\section{INTRODUCCIÓN}

El libro editado por la editorial Biblos corona una larga investigación que Débora Gorban y Ania Tizziani vienen desarrollando desde el año 2008. Un primer punto que debe destacarse es la importancia de contar con un libro escrito a dos manos, dos cuerpos y dos voces en un contexto que incentiva las carreras individuales de investigación, demostrando la importancia y las ganancias que resultan de las investigaciones colectivas en las ciencias sociales.

¿Cada una en su lugar? Trabajo, género y clase en el servicio doméstico tiene como objeto de estudio las relaciones de trabajo que se establecen en el servicio doméstico ${ }^{1}$ de los hogares de la Ciudad de Buenos Aires. Sin embargo, se trata de una obra que desborda ampliamente el análisis de su objeto. A lo largo de sus páginas se transitan grandes hitos de la sociología: las relaciones de poder, el concepto de trabajo, las interacciones cotidianas, las jerarquías y sus sentidos, el debate interseccional, el análisis de la construcción y reproducción de mecanismos de diferenciación y jerarquización, y se dialoga con otras disciplinas críticas, como el feminismo.

De esta manera, las autoras "usan" el servicio doméstico para hablar de procesos sociales mucho más amplios. Tal como lo señalan en el libro:

"el servicio doméstico es pensado como un lugar crítico para reflexionar en torno de la manera en que se construyen y se reproducen, en la práctica cotidiana, mecanismos de diferenciación y de jerarquización social, basados en el género, la clase, la etnicidad y la racialidad"(Gorban y Tizziani, 2019, p. 12).

¿Cada una en su lugar? Trabajo, género y clase en el servicio doméstico es también un libro de época que dialoga con investigaciones recientes sobre los temas que aborda. Este intercambio reflexivo enriquece el contenido del libro y permite ir delineando un campo de estudio: el trabajo de las mujeres de sectores populares.

El modo en el que deciden avanzar en este camino supone el recorrido por múltiples técnicas de investigación social: entrevistas, etnografías, análisis de libros y noticias sobre el servicio doméstico, reflexiones sobre toda charla, informal o pública, sobre la temática que presenciaran. Ante la dificultad de presenciar "in situ" el servicio doméstico, por su pertenencia al "mundo privado", el trabajo de campo fue realizado en diferentes espacios que recorren las trabajadoras: la calle, las plazas, el sindicato. La presencia de las autoras en los lugares donde transitan las empleadas domésticas habilita el registro de escenas significativas que inician algunos de los capítulos del libro, permitiendo introducir a los y las lectores en el "mundo de sentido" (Schutz, 2003) de las mujeres empleadas en el servicio doméstico. 
Una de las decisiones fundamentales que toman las autoras en términos metodológicos es la asunción de una tensión latente en las investigaciones académicas sobre servicio doméstico: la ubicación en el espacio social de quienes investigan y su cercanía (y muchas veces pertenencia) al mundo de las y los empleadores. Débora Gorban y Ania Tizziani a lo largo de los capítulos que componen el libro van dando cuenta de sus posicionamientos objetivos para así poder reflexionar sobre el modo en que sus propias representaciones sobre el trabajo que analizan, compartidas por otras mujeres de sectores medios y altos, inciden en la investigación. Esta "alerta epistemológica" les permite visibilizar y tomar distancia de sus preconceptos durante el trabajo de campo, el análisis de los datos y el proceso de escritura.

En este proceso de toma de distancia es especialmente sugerente el análisis de uno de los supuestos que organiza la mirada sobre el servicio doméstico de ciertos sectores sociales: aquel que lo define como un "mal trabajo", desvalorizado y desvalorizante, que llevaría a toda mujer que lo ejerza a desear la movilidad hacia otra ocupación. Como se señala en el libro, el simple hecho de enunciar la pregunta sobre la salida del trabajo por parte de las investigadoras reproduce la desvalorización sobre la ocupación analizada y sobre las propias mujeres que lo realizan. Esta concepción niega la posibilidad de que sea posible "elegir voluntariamente" ser empleada doméstica, sin embargo, algunas de las trabajadoras entrevistadas en el libro dan cuenta de la complejidad de estas "opciones" laborales. Decidir, entre otros empleos, el del empleo doméstico no impide su caracterización como un empleo realizado en pésimas condiciones laborales. No obstante, la precariedad es compartida con otras ocupaciones presentes en sus trayectorias sociales y horizontes de posibilidades laborales. Solo es posible comprender estas elecciones estando dispuestas a dejarse tensionar por los mundos de sentido analizados.

El contenido del libro abarca múltiples temáticas que podrían ser presentadas "inextenso", sin embargo, me limitaré a señalar aquellos aspectos que tienen una potencialidad en el desarrollo de una agenda de investigación sobre el trabajo de las mujeres de sectores populares.

\section{Caracterización Del trabajo}

El libro explora las condiciones en la que se ejerce el servicio doméstico, el espacio en que se realiza, las actividades que nuclea. Débora Gorban y Ania Tizziani señalan las especificidades, pero también sus puntos en común con otras ocupaciones que las mujeres de sectores populares tienen "a mano".

Entre las especificidades, resaltan que se trata de una actividad que se produce en el seno de la intimidad del hogar y que reúne prácticas, personas y esferas de experiencia que suelen pensarse como separadas. El elemento central del trabajo es su desvalorización por parte de la sociedad y, cotidianamente, por parte de la empleadora.

Otro aspecto singular del servicio doméstico es el espacio en que se realiza. La vivienda se convierte en espacio de trabajo, pero debe seguir siendo el ámbito privado de la familia empleadora. De esta manera, la vida cotidiana familiar y las relaciones laborales se cruzan necesariamente. ¿Espacio de intimidad o espacio laboral? El solapamiento de estos espacios produce la necesidad, por parte de la familia empleadora, de construir límites que permitan mantener las distancias: se definen zonas transitables, habitables y prohibidas, prácticas tolerables y otras que no se permiten de modo explícito o implícito. El hogar es significado como el lugar de la intimidad y debe seguir siéndolo a pesar de la presencia de la trabajadora.

\section{Caracterización de las trabajadoras}

El análisis sobre las trabajadoras supone un enfoque "interseccional”, tantas veces declamado y tan pocas utilizado en el análisis contemporáneo de los fenómenos sociales empíricos. En este caso, las autoras no lo definen como tal, pero lo ejercen. Nuevamente en esta dimensión hacen partícipes a los y las lectores de una 
decisión clave: la selección de las categorías a partir de las cuales van a reflexionar sobre el posicionamiento social de las trabajadoras habilitando, en este mismo gesto, otras opciones. Las autoras deciden trabajar sobre las interrelaciones entre el género, la clase social y la racialización. A partir de ello, nos invitan a pensar la jerarquía entre mujeres, algo incómodo para cierto tipo de pensamiento feminista. Una vez más, como a lo largo del todo el libro, los potenciales debates no se eluden, sino que se evidencian y se toman posiciones ante ellos.

Los condicionamientos raciales, de clase y de género atraviesan la totalidad del análisis que sostiene el libro. En primer lugar, el servicio doméstico es un empleo globalmente realizado por mujeres pertenecientes a los sectores populares tanto por origen o como resultado de desplazamientos migratorios. Sin embargo, el libro logra remarcar la singularidad del contexto local historizando la relación laboral. A partir de ello, se realiza un análisis situado y localizado de la particular historia del mundo del trabajo argentino y sus formas de jerarquización, destacando la importancia de la racialización del o de la subordinado/a. Al historizar el servicio doméstico las autoras pueden afirmar la existencia de una continuidad presente en los países latinoamericanos: las trabajadoras domésticas siguen siendo reclutadas entre las mujeres menos privilegiadas de la sociedad, lo que implica el establecimiento de una relación jerarquizada entre mujeres pobres y acomodadas.

Comprender quiénes son las trabajadoras domésticas supone también comprender sus trayectorias. En el libro se detallan tres trayectorias laborales: una "hacia" (llegada), otra que muestra las carreras dentro del servicio doméstico y la tercera se centra en la "salida" del empleo. En esta descripción se destaca la fluidez de las entradas y salidas dentro del sector que funciona como una red de contención en itinerarios marcados por la vulnerabilidad.

El análisis de las trayectorias laborales de las trabajadoras les permite a las autoras desandar ciertas certezas del sentido común y académico y mostrar que el servicio doméstico no es siempre una inserción transitoria. Por el contrario, tal como concluyen también otras investigaciones desarrolladas en otras latitudes, la movilidad hacia otras formas de trabajo asalariados suele ser limitada.

\section{Caracterización de las empleadoras Y Del vínculo establecido con las TRABAJADORAS}

La desvalorización social del trabajo se reproduce cotidianamente por parte de la empleadora. Como se señala en el libro "La inferioridad de las trabajadoras constituye la condición de posibilidad de la relación laboral" (Gorban y Tizziani, 2019, p. 97). Será central entonces mantener la "inferioridad” de la trabajadora. Una inferioridad que debe ser controlada para ser garantizada.

A lo largo de tres capítulos del libro, Débora Gorban y Ania Tizziani nos introducen en el análisis de las formas de reproducción de la desigualdad que garantiza que "cada una ocupe su lugar", un elemento central del servicio doméstico que nos anticipan desde el título del libro. Para las autoras, la función ideológica del servicio doméstico es "sostener el valor desigual de los seres humanos" (Gorban y Tizziani, 2019, p.85). Las empleadoras reproducen y definen estereotipos que localizan social, económica y simbólicamente a las empleadas. El papel socialmente esperado de quienes trabajan en el servicio doméstico es la aceptación de esta ubicación que supone su rol de empleadas. La cotidianidad del servicio doméstico supone mantener la distancia social entre la empleada y quienes la emplean. Este aspecto, tan remarcado en el servicio doméstico, sirve de guía para pensar otras formas de jerarquización que subalternizan a los sectores populares en diferentes esferas de la sociedad.

El libro nos sitúa en los relatos de las empleadoras y sus temores frente a la empleada en lo que definen como las "amenazas a la inferioridad" (Groban y Tizziani, 2019, p. 101) ¿Cuándo una empleada se vuelve amenazante? Cuando existe la posibilidad de que no se ajuste a las imágenes estereotipadas ni sostengan sus roles atribuidos. Que se “deje ver” es desubicado. Que su presencia sea disruptiva es desubicado. Como señala 
Pascale Molinier (2008) al reflexionar sobre el trabajo y los saberes de las cuidadoras, se trata de un tipo de trabajo que debe ser discreto, es decir que solo se visibiliza cuando se encuentra mal hecho.

De esta manera, el servicio doméstico es evaluado por parte de las empleadoras mucho más por las características morales de las trabajadoras que por las prácticas laborales que realizan. Esta evaluación toma la forma de "recomendaciones" que se constituyen en la principal vía para acceder a este tipo de empleo. Cuando se recomienda una empleadora se denota especialmente su capacidad de ser "ubicada", de no hacerse notar, de volverse invisible y la garantía de que "no robará. Por lo tanto, se trata de una evaluación moral sobre la trabajadora y no sobre las técnicas y saberes de su oficio.

Pero lejos de quedarse con esta caracterización, el libro nos invita a pensar también en la ambigüedad del vínculo establecido entre empleada y empleadora donde lo afectivo se superpone con lo laboral y en el que, aun manteniendo inmune la distancia social entre ambas, es posible pensar en presencia de un intercambio afectivo. Recordemos como ejemplo la película Roma (Alfonso Cuarón, 2018) que intenta narrar estas formas ambiguas del vínculo, no exentas de cariño entre las partes. Por otro lado, es esta misma ambigüedad afectiva la que opera en la invisibilización de la relación laboral.

Tal como lo señalamos anteriormente, el servicio doméstico depende de que cada una se quede en su lugar. La ambigüedad que caracteriza la relación laboral entre empleadas y empleadoras demanda entonces la necesidad de generar "repertorios de demarcación" (Gorban y Tizziani, 2019, p. 111) por parte de las empleadoras. Se trata de "un conjunto de prácticas para establecer límites y distinciones, que expresan procesos de inferiorización que permiten mantener las jerarquías” (Gorban y Tizziani, 2010, p. 104). Estos repertorios se construyen con los recursos presentes en el vínculo establecido y en el espacio en que se desarrolla la actividad y resultan efectivos cuando se naturalizan. En este sentido, resulta revelador el Capítulo 5 del libro, enfocado en las prácticas alrededor de la comida. El control permanente sobre los alimentos se transforma en un recordatorio constante de que ese hogar no es el lugar de las empleadas. De esta manera, no se trata de controlar la comida sino a las mujeres trabajadoras.

\section{Dimensión Colectiva del SERVicio doméstico}

Los últimos capítulos abordan la dimensión colectiva del servicio doméstico. Nuevamente desafiando algunos lugares comunes que enfatizan la atomización del trabajo y la personalización de la relación laboral, el libro ahonda en los recorridos por el espacio público que las trabajadoras realizan al desarrollar actividades propias de su empleo pero que desbordan el espacio doméstico (la plaza, la salida de la escuela, el supermercado). En estos lugares pueden encontrarse con semejantes, desarrollar otras sociabilidades, y ganar un margen de autonomía mayor al que poseen en el "adentro". Es decir, el significado del "adentro" y el "afuera" toma otra connotación. Un elemento muy interesante es la idea de que en estos espacios del afuera del hogar las empleadas construyen una "cultura del trabajo" (Gorban y Tizziani, p. 166), es decir, una serie de valores, prácticas y saberes compartidos en los que se incluye una definición valorizada tanto de las actividades de cuidados que realizan como de los saberes y las competencias que se requieren para ejercerlas. De esta manera, la "cultura del trabajo" de las empleadas vislumbra una dimensión central compartida por las empleadas domésticas: la valorización del trabajo de cuidados. Si bien la sociedad en general y la política en particular desvalorizan e invisibilizan las prácticas de cuidado, esto no necesariamente se traduce en una desvalorización por parte de las propias mujeres. Para algunas, especialmente aquellas que pertenecen a los sectores populares, las actividades de cuidado constituyen prácticas valiosas y valorizantes. Se trata de una tensión entre diferentes experiencias de clase que se escenifica en la relación entre empleadas y empleadoras. En las plazas, las colas, las escuelas, se colectivizan experiencias y se circula información sobre salarios y condiciones de trabajo que permite saber lo que resulta aceptable como nivel de salario y lo que no. Los arreglos individualizados y personalizados que caracterizan al servicio doméstico adquieren así, acotada, visibilidad pública. Si bien no se trata de un tema abordado 
el libro, la idea de una experiencia colectiva en efímera pero práctica recuerda a lo que sucede en las redes sociales donde diferentes empleadas se contactan, comparten experiencias de trabajo, su salario, se aconsejan. Las redes y las conversaciones en las plazas y otros lugares del "afuera" no anulan la atomización y las dificultades de pensar la acción colectiva en este tipo de empleo, pero habilitan a pensar la posibilidad de encuentros entre empleadas con recursos diferentes a los presentes en otros sectores laborales.

Además de los salarios y la construcción de las condiciones aceptables, los intercambios entre empleadas contienen otro tema recurrente: las propias empleadoras. Bajo la forma de chistes, se filtran críticas morales sobre los estilos de vida y la valorización de diferentes prácticas, especialmente las domésticas y las de cuidado. Para Débora Gorban y Ania Tizziani estos "chismes" no deben comprenderse como resistencias a la inferiorización, pero sí son las bases de la elaboración de una visión crítica de los estilos de vida de clase media y alta conformando un discurso que constituye su identidad de clase a través de la diferenciación y la distancia con las empleadoras. Esa distancia social se erige a partir de diferentes ejes: el nivel de ingreso, las formas de consumo y la utilización del tiempo, especialmente, la crítica al "desprecio" por el trabajo de cuidado.

Esta reseña ha dejado fuera otras discusiones relevantes sobre las cuales no podré detenerme. Pero quisiera terminar destacando que las autoras desarrollan su investigación atravesando las oposiciones binarias del pensamiento moderno occidental y su expresión en la organización del mundo del trabajo: la contraposición entre casa y trabajo, intimidad y distancia, adentro y afuera, público y privado, trabajo productivo y reproductivo. Al tensionar estas dicotomías se visibilizan dimensiones del trabajo que fueron poco consideradas en su estudio: la dimensión relacional, la centralidad del cuerpo, los afectos y las emociones. El libro culmina con una invitación a seguir investigando sobre la presencia de estas tensiones y dimensiones en otras ocupaciones relacionadas con los cuidados o con lo que las autoras definen como "trabajos íntimos". Ocupaciones diferenciadas pero que están interconectadas a partir de compartir ciertos atributos.

La placentera experiencia de leer el libro, especialmente el análisis sobre el miedo a la "desubicación" de las empleadas por parte de las empleadoras, me recordó una y otra vez la tradición plebeya de los sectores populares en la Argentina. Su ausencia, en las experiencias de las empleadas podría mostrar los posibles límites de lo plebeyo en las relaciones sociales que se desenvuelven en el espacio íntimo o en relaciones laborales que dependen de la inferiorización simbólica y política del empleado/a. Pero también su presencia constante en tanto espectro de lo posible que debe ser controlado a partir del despliegue de estrategias de "ubicación" y disciplinamiento. ¿Funcionará del mismo modo el vínculo entre empleadora y empleada en tradiciones políticas de los sectores populares diferentes?

El libro no nos da una respuesta a este interrogante, pero estimula esta y otras grandes preguntas para seguir pensando el mundo del trabajo y las formas en que es experimentado por las mujeres de sectores populares.

\section{Referencias bibliográficas}

Gorbán D. y Tizziani A. (2019). ¿Cada una en su lugar? Trabajo, género y clase en el servicio doméstico. Buenos Aires: Editorial Biblos.

Molinier, P. (2008). Trabajo y compasión en el mundo hospitalario. Una aproximación a través de la psicodinámica del trabajo. Cuadernos de Relaciones Laborales, 26 (2).

Shutz, A. (2003). Estudios sobre teoría social. Escritos II. Buenos Aires: Editorial Amorrortu.

\section{Notas}

1 Voy a usar la misma categoría que usan las autoras y cuya elección justifican en las primeras páginas del libro. 